\title{
Pemanfaatan limbah kelapa sawit untuk budidaya jamur merang dalam upaya perbaikan ekonomi desa: Pengabdian kepada masyarakat di Desa Kampung Baru, Kabupaten Pelalawan
}

\author{
Djaimi Bakce ${ }^{1 *}$, Almasdi Syahza ${ }^{2}$, Syaiful Bahri ${ }^{3}$, Mitri Irianti ${ }^{2}$, RM Riadi ${ }^{2}$, dan \\ Brilliant Asmit ${ }^{2}$
}

${ }^{1}$ Fakultas Pertanian, Universitas Riau

${ }^{2}$ Fakultas Keguruan dan Ilmu Pendidikan, Universitas Riau

${ }^{3}$ Fakultas Teknik, Universitas Riau

*djaimibakce@yahoo.com

\begin{abstract}
Abstrak. Di Desa Kampung Baru Kecamatan Ukui Kabupaten Pelalawan tersedia limbah kelapa sawit berupa Tandan Kosong Kelapa Sawit (TKKS) dari pabrik pengolahan kelapa sawit. TKKS dapat dimanfaatkan untuk dijadikan media budidaya jamur merang. Untuk mengoptimalkan pemanfaatan potensi ini dilaksanakan pelatihan dan pendampingan kepada kelompok masyarakat dan lembaga ekonomi lokal dalam bentuk pengembangan produk jamur merang dan penguatan kelembagaan. Pelaksanaan kegiatan dengan cara melakukan pendampingan secara berkala kepada masyarakat desa sebanyak 20 orang. Disamping itu juga diberikan pengetahuan tentang pemasaran produk jamur merang sehingga berdampak terhadap perubahan pendapatan dan perekonomian masyarakat. Kegiatan berlokasi di daerah pengembangan biogas plant. Capaian hasil kegiatan adalah peserta telah dapat membudidayakan jamur merang mulai dari proses menyiapkan media TKKS hingga pemanenan. Kegiatan ini belum sampai pada tahap perhitungan hasil panen dan pemasaran, tetapi peserta sudah mendapat gambaran estimasi produk jamur merang. Pada luas areal panen $144 \mathrm{~m} 2$ memproduksi jamur merang sebanyak $34.56 \mathrm{~kg}$ per hari.
\end{abstract}

Kata kunci: jamur merang; biogas plant; tandan kosong kelapa sawit; ekonomi pedesaan; pelatihan; pengabdian kepada masyarakat

\begin{abstract}
There is oil palm waste in the form of Oil Palm Empty Bunches (TKKS) in the Village of Kampung Baru, Subdistrict of Ukui, Pelalawan Regency. TKKS can be used as a medium for straw mushroom cultivation. To utilize this potential, the team provided the training and assistance in developing mushrooms product and its institutional strengthening to the community groups and local economical institutions. The team implement the activities by conducting community assistance to 20 village people. Other than that, the team gave the marketing knowledge of the mushroom product, so that it could increase the community income and economy. The activities located in the biogas plant development area. The result is participants have been able to cultivate mushroom from the process of setting the medium to harvesting. This activity has not reached the stage of harvest calculation and marketing yet. But the participants have got a mushroom products estimation that in the $144 \mathrm{~m} 2$ harvested area produces $34.56 \mathrm{~kg}$ of mushroom is per day.
\end{abstract}

Keywords: mushroom; biogas plant; oil palm empty bunches; rural economy; training; community service

To cite this article: Bakce, D., A. Syahza, S. Bahri, M. Irianti, RM Riadi, \& B. Asmit. 2019. Pemanfaatan Limbah Kelapa Sawit untuk Budidaya Jamur Merang dalam Upaya Perbaikan Ekonomi Desa: Pengabdian kepada Masyarakat di Desa Kampung Baru, Kabupaten Pelalawan. Unri Conference Series: Community Engagement 1: 235-242 https://doi.org/10.31258/unricsce.1.235-242

(C) 2019 Authors

Peer-review under responsibility of the organizing committee of Seminar Nasional Pemberdayaan Masyarakat 2019 


\section{PENDAHULUAN}

Provinsi Riau merupakan provinsi yang memiliki luas lahan perkebunan kelapa sawit terluas di Indonesia dengan luas total 2,3 juta Ha pada tahun 2015 (Direktorat Jenderal Perkebunan, 2016). Luas lahan perkebunan kelapa sawit ini meningkat dari tahun ke tahun. Tahun 2015 produksi perkebunan kelapa sawit Provinsi Riau mencapai 7.529.614,81 ton.

Potensi ketersediaan TKKS di Provinsi Riau cukup besar, data produksi TBS di Provinsi Riau pada tahun 2017 diperkirakan mencapai 8.721.148 ton per tahun (Direktorat Jenderal Perkebunan, 2016). Apabila setiap ton TBS dihasilkan $200 \mathrm{~kg}$ TKKS (20\%) maka akan dihasilkan 1.744.229 ton TKKS per tahun.

Desa Kampung Baru yang terletak di Kecamatan Ukui Kabupaten Pelalawan sebagian besar pekerjaan masyarakatnya sebagai petani. Disana berdiri PT Inti Indosawit Subur yang tersedia secara cuma cuma dan berkelanjutan TKKS. Selain digunakan sebagai bahan bakar pemanfaatan limbah sawit dalam bentuk TKKS dapat digunakan dalam kegiatan seperti pertanian sebagai media tumbuh jamur. Jamur yang tumbuh menggunakan media limbah sawit TKKS pada umumnya adalah jenis jamur yang edible atau dapat dimakan. Limbah sawit TKKS sisa media jamur menjadi sebuah permasalahan baru bagi masyarakat, dimana limbah tersebut sulit didegradasi sehingga semakin lama semakin terjadi penumpukan.

Dalam keadaan alami tandan kosong kelapa sawit jika dibiarkan diruang terbuka akan banyak ditumbuhi berbagai macam jamur. Siregar dan Ritonga (2014); Hidayati dkk (2015); serta Wirasaputra (2018) telah melakukan penelitian pemanfaatan TKKS sebagai media tanam jamur merang. Penelitian-penelitian tersebut menyatakan bahwa TKKS merupakan media tanam yang cocok untuk jamur merang karena dapat meningkatkan produktivitas jamur merang.

Penanaman jamur merang dilakukan pada kumbung jamur. Pada kumbung terdapat 12 rak dimana masingmasing rak memiliki 3 tray. Setiap tray berukuran $4 \times 1 \mathrm{~m}$. Secara keseluruhan dibutuhkan tandan kosong sawit sebanyak 8 ton untuk media tanam jamur selama 2 bulan (Hasanudin, 2018). Produksi jamur merang membutuhkan bibit sebanyak 1 log bibit per $\mathrm{m}^{2}$ media tanam ( 1 log bibit memiliki berat 300 gram) (Harnanik, 2017). Jamur merang mulai dapat dipanen pada hari ke 10 penanaman hingga hari ke 25, sehingga kebutuhan bibit berjumlah $288 \log$ untuk 2 bulan. Setiap kumbung jamur dapat menghasilkan $200 \mathrm{~kg}$ jamur merang tiap kali panen.

Adapun metode produksi jamur merang dilakukan melalui beberapa tahapan (Harnanik, 2017), yaitu:

1. Tandan kosong dapat diperoleh di pabrik pengolahan sawit dihamparkan selama empat hari untuk memberi kesempatan jamur berwarna oranye untuk tumbuh sehingga kadar minyak berkurang. Tandan sawit yang dibiarkan lewat 20 hari hasilnya kurang baik.

2. Tandan selanjutnya dicuci untuk menghilangkan minyak tersisa atau direndam semalam dalam bak.

3. Tandan yang telah dicuci ditumpuk dengan tinggi sekitar 1 meter dan tiap lapis tandan ditambah kapur dan dedak. Pengomposan dilakukan 8-14 hari. Pada hari ke 4 dan 8 dilakukan pembalikan

4. Selanjutnya tandan kosong disusun pada tray kumbung jamur. Untuk jamur merang hitam tumpukan jangan terlalu tebal, sedangkan untuk jamur merang putih perlu media yang lebih tebal

5. Tahapan berikut adalah pasteurisasi yang dilakukan dengan cara mengalirkan uap panas kedalam kumbung jamur sekitar 5-7 jam. Suhu kumbung harus mencapai $70^{\circ} \mathrm{C}$ minimal 2 jam.

6. Bibit jamur ditabur diatas tumpukan tandan sawit segera setelah pasteurisasi namun suhu dalam media sudah turun sekitar $30^{\circ} \mathrm{C}$.

7. Pemeliharaan berupa buka tutup jendela, pencahayaan dan penyiraman dilakukan dari hari ke-5 sampai habis panen.

8. Penyiraman dilakukan hanya apabila diperlukan, yaitu jika media tanam dirasa telah cukup kering, sehingga penyiraman tidak harus dilakukan setiap hari.

9. Jamur merang dapat dipanen sekitar hari ke-10 setelah tanam. Panen dilakukan setiap hari pagi atau sore hari.

Dalam rangka untuk memanfaatkan limbah kelapa sawit dalam bentuk tandan kosong kelapa sawit, Lembaga Penelitian dan Pengabdian kepada Masyarakat (LPPM) Universitas Riau bekerjasama dengan Kementerian Lingkungan Hidup dan Kehutanan (KLHK) Republik Indonesia untuk melaksanakan kegiatan Penyusunan Studi Kelayakan dan Pembangunan Biogas Plant beserta fasilitas pendukungnya di Desa Kampung Baru Kecamatan Ukui Kabupaten Pelalawan pada tahun 2018. Salah satu rekomendasi dari kegiatan tersebut adalah pembentukan unit pengelola Biogas Plant, dimana unit ini disarankan di bawah atau sebagai bagian dari Badan Usaha Milik Desa Mukti Raharja Desa Kampung Baru. 
Pelatihan tentang jamur merang terinspirasi dari penelitian pemanfaatan tandan kosong kelapa sawit sebagai media tanam jamur merang yang dilakukan oleh Siregar dan Ritonga (2014), Hidayati dkk (2015), serta Wirasaputra (2018). Penelitian-penelitian tersebut menyatakan bahwa tandan kosong kelapa sawit merupakan media tanam yang cocok untuk jamur merang karena dapat meningkatkan produktivitas jamur merang.

Tandan kosong sawit sisa media tanam jamur merang serta kotoran sapi bioaktivator digunakan untuk memproduksi biogas. Total produksi biogas diperkirakan 8 - $11 \mathrm{~m} 3$ per hari (Hasanudin, 2018). Ketersediaan tandan konsong kelapa sawit sisa media tanam jamur merang serta keberadaan kelompok peternak sapi pedaging yang menghasilkan kotoran sapi menunjukkan kelayakan proses produksi dari sudut bahan baku. Hasil penelitian Nasrul dan Maimun (2009) menunjukkan bahwa proses dekomposisi terjadi lebih efisien dan cepat jika menggunakan TKKS yang sudah ditumbuhi jamur.

Disamping melakukan pelatihan dan pendampingan dari aspek teknis, dalam pelaksanaan pengabdian kepada masyarakat ini juga dilakukan pelatihan dan pengembangan kapasitas sumberdaya manusia dan kelembagaan ekonomi masyarakat. Menurut Hasibuan (2005), pengertian Sumberdaya Manusia (SDM) adalah kemampuan terpadu dari daya pikir dan daya fisik yang dimiliki oleh individu. Pelaku dan sifatnya dilakukan oleh keturunan dan lingkungannya, sedangkan prestasi kerjanya dimotivasi oleh keinginan untuk memenuhi kepuasannya (kebutuhannya). SDM dari daya pikir dan daya fisik setiap manusia, atau dengan kata lain kemampuan setiap manusia ditentukan oleh daya pikir dan daya fisiknya.

Pelatihan dilakukan untuk meningkatkan dan mengembangkan sumberdaya manusia seseorang ataupun kelompok sasaran. Pada hakekatnya pengembangan sumberdaya manusia mempunyai dimensi luas yang bertujuan meningkatkan potensi yang dimiliki oleh sumberdaya manusia, sebagai upaya meningkatkan profesionalisme dalam organisasi (Cascio dan Awad, 1981).

Tujuan kegiatan ini adalah terbangunnya satu unit budidaya jamur merang yang terintegrasi dengan kegiatan biogas plant. Untuk melatih masyarakat tentang budidaya jamur merang dengan memanfaatan limbah tandan kosong kelapa sawit menjadi media tumbuh jamur. Meningkatkan ekonomi masyarakat Desa Kampung Baru Kecamatan Ukui Kabupaten Pelalawan melalui bududaya jamur merang.

Kegiatan pengabdian ini dilakukan oleh tim pengabdian dari LPPM Universitas Riau. Kegiatan pengabdian kepada masyarakat ini akan dilaksanakan melalui mekanisme pendampingan secara berkala kepada kelompok masyarakat dan Lembaga perekonomian desa yaitu Unit Usaha Biogas Plant, BUMDes, Masyarakat Penerima Manfaat (beneficiaries), dan Ibu PKK.

Sebagaimana telah diuraikan pada bagian pendahuluan bahwa salah satu rekomendasi dari kegiatan Penyusunan Studi Kelayakan dan Pembangunan Biogas Plant di Desa Kampung Baru Kecamatan Ukui Kabupaten Pelalawan pada tahun 2018 adalah pendampingan pemanfaatan jamur merang secara berkala dan pembentukan unit pengelola Biogas Plant, dimana unit ini disarankan di bawah atau sebagai bagian dari Badan Usaha Milik Desa (BUMDes) Mukti Raharja Desa Kampung Baru. Sampai saat ini belum ada kejelasan yang nyata tentang bagaimana implementasi manajemen pengelolaan unit usaha Biogas Plant pada khususnya dan BUMDes Mukti Raharja secara umum.

\section{METODE PENERAPAN}

Tempat pelaksanaan kegiatan pengabdian kepada masyakat Di Desa Kampung baru Kecamatan Ukui Kabupaten Pelalawan. Kegiatan dilaksanakan selama lima bulan, dimulai dari Juli 2019 dan direncanakan sampai November 2019.

Strategi pelaksanaan kegiatan pengabdian kepada masyarakat ini dilaksanakan melalui pelatihan dan pendampingan secara berkala oleh narasumber dan tim pengabdian kepada masyarakat Universitas Riau. Pendampingan dilakukan kepada kelompok masyarakat dan Lembaga perekonomian desa yaitu Ibu PKK dan BUMDes.

Mekanisme pelaksanaan kegiatan pengabdian kepada masyarakat dilkukan dengan langkah-langkah sebagai berikut:

1. Sosialisasi Program

Sosialisasi dilakukan kepada masyarakat, aparat desa, dan komponen masyaraat lainnya yang ada di Desa Kampung Baru untuk memberikan gambaran mengenai rencana kegiatan pengabdian yang akan dilakukan. Selain itu, sosialisasi ini juga bertujuan untuk melihat respon masyarakat terhadap kegiatan yang akan dilakukan serta menampung berbagai aspirasi masyarakat mengenai permasalahan dan potensi desa yang ada di Desa Sepahat. 


\section{Pelatihan Budidaya Jamur Merang}

Pelatihan ini merupakan pelatihan yang diberikan kepada masyarakat untuk memanfaatkan limbah kelapa sawit yang selama ini tidak digunakan menjadi produk unggulan desa. Usaha ini nantinya diharapkan mampu menjadi salah satu opsi kegiatan ekonomi masyarakat dalam memenuhi kebutuhan hidup mereka. Pelatihan ini mengajarkan masyarakat untuk memanfaatkan tandan kosong kelapa sawit. Pelatihan ini menggunakan pembelajaran interaktif, dimana pendidikan informal ini akan mensukseskan knowledge transfer kepada peserta (Syahza et al., 2018; Ndungi et al., 2017).

Langkah langkah yang dilakukan dalam pemanfaatan limbah kelapa sawit untuk budidaya jamur merang adalah sebagai berikut:

(1) Melakukan persiapan tandan kosong sawit

(2) Melakukan fermentasi tandan kosong sawit dengan pencampuran dengan kapur dolomit dan bekatul

(3) Setelah proses fermentasi, tandan kosong sawit dipindahkan ke rak jamur di dalam kumbumg jamur

(4) Kemudian dilakukan sterilisasi dengan mengalirkan uap (steam) ke dalam kumbung jamur,

(5) Kemudian menyemai bibit jamur ke tandan kosong sawit yang telah disterilisasi,

(6) Kemudian dibiarkan beberapa hari menunggu tumbuhnya jamur,

(7) Kemudian jamur yang sudah cukup umur (sebelum mekar) siap dilakukan pemenenan.

(8) Melakukan analisis finansial budidaya jamur dengan memanfaatkan limbah tandan kosong kelapa sawit (TTKS).

(9) Merancang model pengelolaan budidaya jamur, mulai dari kepemilikan, organisasi, maupun kelembagaan.

3. Pendampingan Pemantapan Hasil budidaya Jamur Merang Pasca Pelatihan

Pendampingan pemantapan pasca pelatihan dilakukan sebagai salah satu cara untuk melihat keberlangsungan kegiatan pelatihan yang sudah dilakukan. Pelatihan yang baik memberi dampak yang positif terhadap kinerja (Danvila del valle et al., 2009), untuk memastikannya tim melakukan pendampingan. Hal ini juga untuk memastikan masyarakat tetap melanjutkan aktivitas merawat jamur merang pasca pelatihan sekaligus memantapkan hasil bududaya jamur sebelum dijual ke pasar.

4. Pendampingan Manajemen Pemasaran Produk

Manajemen pemasaran merupakan bagian yang sangat penting (Gray et al., 2007) dilakukan agar masyarakat mempunyai kemampuan dalam melakukan pemasaran produk-produk yang telah dihasilkan. Perlu memberi pengetahuan bahwa penjualan produk dengan cara konvensional tidak cocok (Brooksbank et al., 2018) untuk memasarkan produk di era modern.

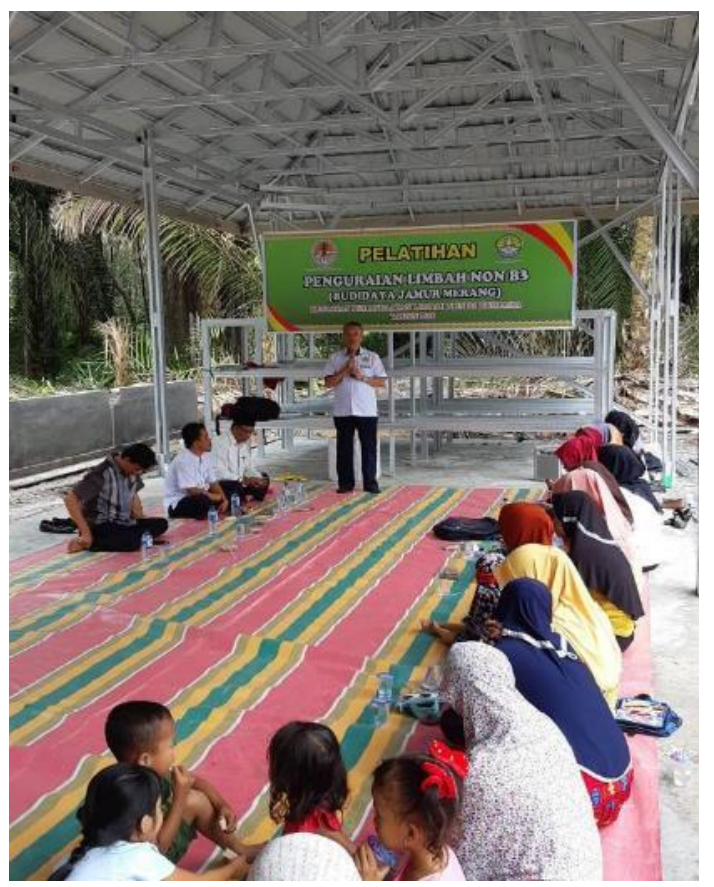

Gambar 1. Pembukaan Acara Pelatihan dan Perkenalan Alat serta Proses Budidaya Jamur 


\section{HASIL DAN KETERCAPAIAN SASARAN}

Kegiatan pengabdian kepada masyarakat ini dilaksanakan melalui mekanisme pendampingan secara berkala oleh Tim dari LPPM Universitas Riau. Pendampingan dilakukan kepada kelompok masyarakat dan Lembaga perekonomian desa yaitu Unit Usaha Biogas Plant, BUMDes, Masyarakat Penerima Manfaat (beneficiaries), dan Ibu PKK. yang berjumlah 20 orang. Selain pendampingan secara berkala, kegiatan pengabdian ini juga akan memberikan berbagai jenis pelatihan yang sesuai dengan potensi yang akan dikembangkan. Rincian kegiatan pengabdian sebagai berikut: (1) pembukaan acara pelatihan dan perkenalan alat serta proses budidaya jamur (Gambar 1); (2) praktek teknik fermentasi, penghamparan TKKS, penambahan dolomit, dan bekatul (Gambar 2); (3) pemindahan TKKS hasil fermentasi ke tray jamur dalam kumbung jamur (Gambar 3), dan; (4) pemeliharaan kumbung jamur (Gambar 4).

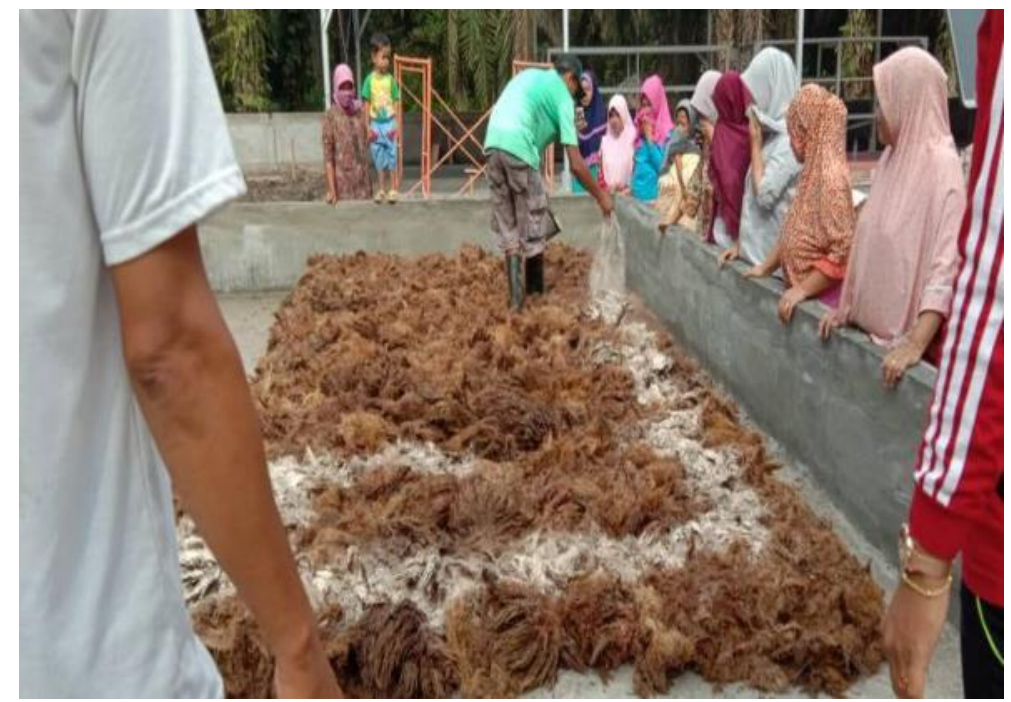

Gambar 2. Proses Fermentasi, Penghamparan TKKS, Penambahan Dolomit, dan Bekatul

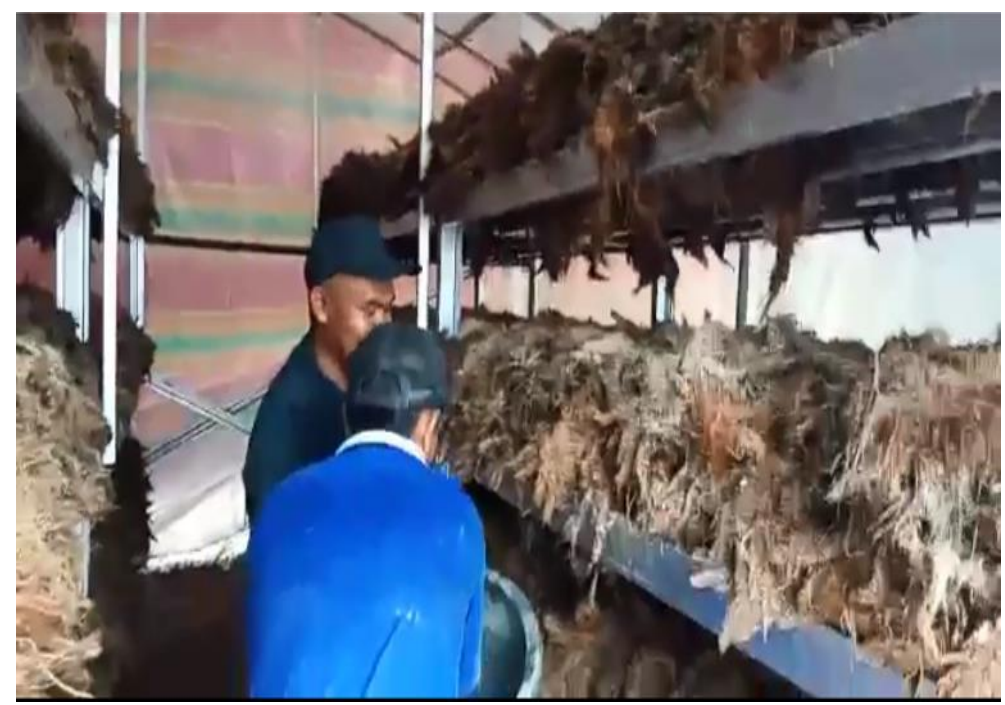

Gambar 3. Pemindahan TKKS Hasil Fermentasi ke Tray Jamur dalam Kumbung Jamur

Hasil kegiatan pembudidayaan jamur merang dengan pemanfaatan tandan kosong kelapa sawit yang berasal dari pabrik pengolahan kelapa sawit oleh peserta masyarakat Desa Kampung Baru di lokasi biogas plant dapat dilihat pada Gambar 5.

Sebagaimana telah dijelaskan pada bagian terdahulu bahwa Biogas Plant yang dibangun dirancang untuk menghasilkan produk jamur merang. Oleh karenanya pada bagian ini akan dijelaskan tentang Estimasi produksi produk yang dihasilkan oleh Biogas Plant tersebut. 


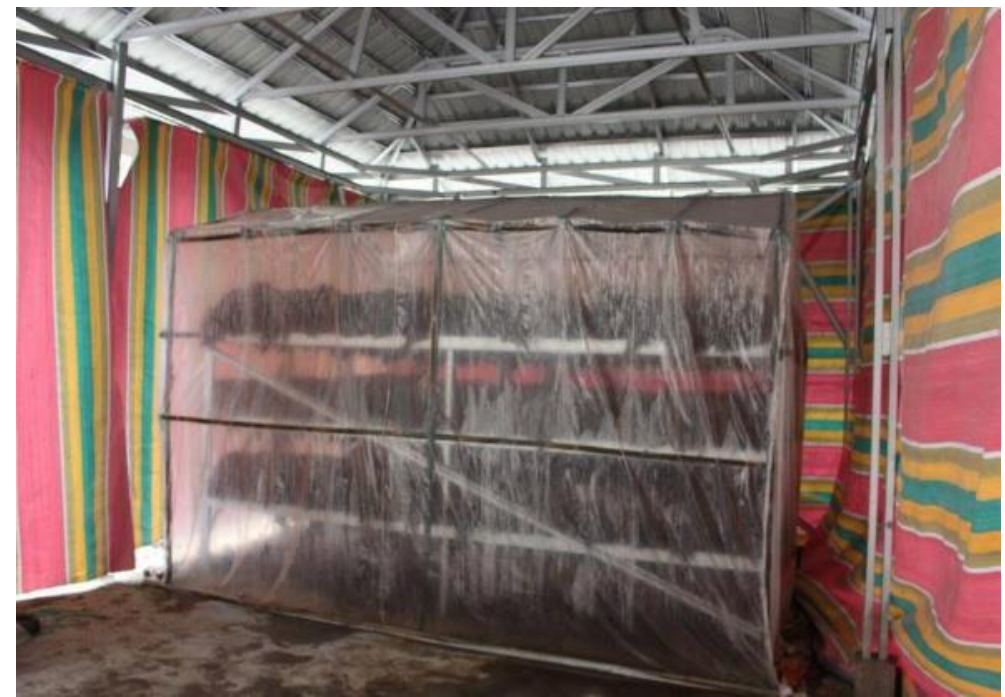

Gambar 4. Kumbung Jamur

Pada Biogas Plant BUMDes Raharja Mukti dibangun kumbung jamur yang terdiri dari beberapa rak dengan total luas $144 \mathrm{~m}^{2}$. Berdasarkan data dari FAO tahun 2016 jumlah produksi jamur di Indonesia sebesar 4,906

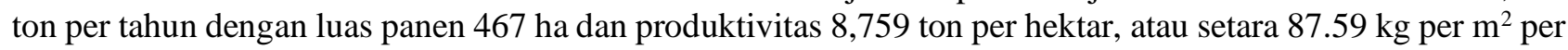
tahun atau $0,239 \mathrm{~kg}$ per $\mathrm{m}^{2}$ per hari. Mengacu pada informasi tersebut maka untuk luas areal panen $144 \mathrm{~m}^{2}$ diperoleh produksi jamur merang sebanyak $34.56 \mathrm{~kg}$ per hari.

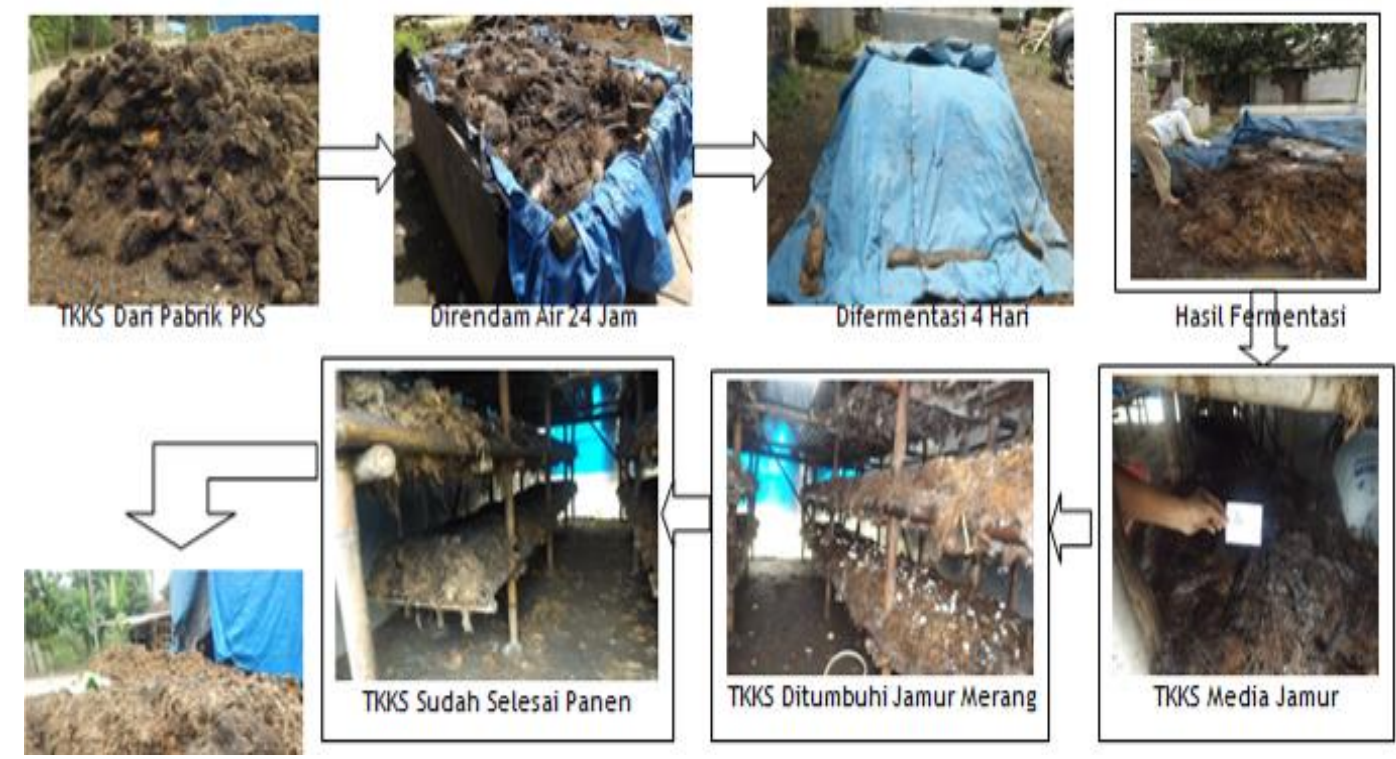

Gambar 5. Aliran Proses Pengolahan Jamur Merang dari TKKS

Selanjutnya mengacu pada teknik budidaya jamur merang, selama satu bulan panen jamur merang selama 20 hari. Dengan asumsi tingkat capaian produksi per luas panen Biogas Plant sebanyak $30 \mathrm{~kg}$ per hari maka dalam satu tahun (240 hari panen) diperoleh produksi jamur merang diperkirakan sebanyak $7.200 \mathrm{~kg}$.

Berdasarkan hasil survei lapang dan browsing internet dari berbagai rujukan diperoleh harga jamur merang berkisar antara $\mathrm{Rp} 20.000-40.000$ per $\mathrm{kg}$. Dengan asumsi bahwa harga jamur merang Rp 25.000 per $\mathrm{kg}$ dan jumlah penjualan $7.200 \mathrm{~kg}$ per tahun maka nilai penjualan jamur merang sebesar Rp 180.000.000 per tahun.

Berdasarkan hasil evaluasi yang dilakukan hal ini disebabkan belum ada serah terima secara resmi dari KLHK melalui Dinas LHK Kabupaten Pelalawan kepada Desa Kampung Baru. Mengingat waktu pelatihan pada kegiatan sebelumnya yang relatif singkat, berdasarkan hasil evaluasi terindentifikasi permasalahan sebagai berikut:

1. Belum optimalnya peran BUMDes Mukti Raharja dalam pengelolaan Biogas Plant dan upaya peningkatan kesejahteraan masyarakat.

2. Belum optimalnya budidaya jamur merang pada Biogas Plant Desa Kampung Baru. 
3. Belum adanya packaging dan merek/brand dari produk-produk Biogas Plant yang dihasilkan.

4. Masih terbatasnya motivasi dan jika kewirausahaan masyarakat di Desa Kampung Baru.

\section{KESIMPULAN}

Pemanfaatan TKKS untuk budidaya jamur merang di lokasi Biogas Plant Desa Kampung Baru Kecamatan Ukui Kabupaten Pelalawan telah dilaksanakan melalui pelatihan dan pendampingan kepada peserta anggota masyarakat Desa Kampung Baru. Kegiatan yang dilakukan mulai dari tahap pengambilan TKKS, fermentasi, pemindahan TKKS hasil fermentasi ke tray jamur dalam kumbung jamur dan pemanenan. Kegiatan ini belum sampai pada tahap perhitungan hasil panen dan pemasaran, tetapi peserta sudah mendapat gambaran estimasi produk jamur merang di desa Kampung pada luas areal panen $144 \mathrm{~m}^{2}$ diperoleh produksi jamur merang sebanyak 34,56 kg per hari. Dari aspek pasar, jamur merang memiliki prospek pasar yang masih terbuka luas pada tingkat lokal, kabupaten, provinsi, nasional maupun pasar internasional.

Selain itu, pada kegiatan tersebut telah dilakukan pelatihan budidaya jamur merang. Mengingat waktu pelatihan yang relatif singkat, walaupun masyarakat penerima manfaat sudah memahaminya, namun masih dirasakan perlu untuk pelatihan untuk penguatan sehubungan dengan budidaya jamur merang, proses produksi pupuk kompos dan pupuk cair. Pelatihan dan pendamping yang tak kalah pentingnya terkait dengan aspek hilir, yaitu penangan pascapanen jamur seperti pembersihan dan packaging, demikian juga halnya dengan pupuk kompos dan pupuk cair memerlukan pelatihan dan pendamping dalam melakukan packaging. Disamping itu juga diperlukan pelatihan dan pendamping dari aspek motivasi dan entrepreneurship serta pemasaran produk Biogas Plant. Hal ini perlu dilakukan untuk menjamin kontinuitas usaha Biogas Plant yang telah dibangun.

\section{UCAPAN TERIMAKASIH}

Kegiatan pengabdian kepada masyarakat ini didanai oleh Universitas Riau melalui Lembaga Penelitian dan Pengabdian kepada Masyarakat Universitas Riau tahun anggaran 2019. Kegiatan ini juga merupakan lanjutan Penyusunan Studi Kelayakan dan Pembangunan Biogas Plant beserta fasilitas pendukungnya di Desa Kampung Baru Kecamatan Ukui Kabupaten Pelalawan yang didanai oleh Kementerian Lingkungan Hidup dan Kehutanan (KLHK) Republik Indonesia pada tahun 2018. Terimakasih diucapkan kepada Mahasiswa Kuliah Kerja Nyata Universitas Riau tahun 2019 dan masyarakat Desa Kampung Baru Kecamatan Ukui Kabupaten Pelalawan yang telah berpartisipasi dan mendukung kegiatan ini.

\section{DAFTAR PUSTAKA}

Brooksbank, R., Z. Subhan, and R. Calderwood. 2018. How applicable are conventional strategic marketing practices in emerging markets? An exploratory study in India. International Journal of Emerging Markets 13(5): 959-979. https://doi.org/10.1108/IJoEM-06-2017-0205

Cascio, W. F., and E. M. Awad. 1981. Human Resources Management: An Information System Approach. Washington DC: Reston Publishing Company.

Danvila del Valle, I., M. A. S. Castillo, and A. Rodríguez-Duarte. 2009. The effects of training on performance in service companies. International Journal of Manpower, 30(4): 393-407. https://doi.org/10.1108/01437720910973070

Direktorat Jendral Perkebunan. 2016. Statistik Perkebunan Indonesia. Jakarta: Sekretariat Direktorat Jenderal Perkebunan.

Gray, B. J., G. G. Ottesen, J. Bell, C. Chapman, and J. Whiten. 2007. What are the essential capabilities of marketers?. Marketing Intelligence \& Planning 25(3): 271-295. https://doi.org/10.1108/02634500710747789

Harnanik, Sri. 2017. Pemanfaatan Tandan Kosong Sawit Sebagai Media Budidaya Jamur Merang. http://sumsel.litbang.pertanian.go.id/BPTPSUMSEL/halkomentar-pemanfaatan-tandan-kosong-sawit-sebagaimedia-budidaya-jamur-merang-2.html. Diakses pada 3 Januari 2019.

Hasanudin, U. 2018. Desain Teknis Fasilitas Pemanfaatan Limbah Non B3 Biomassa Tandan Kosong Kelapa Sawit (TKKS) Untuk Energi, Pangan, dan Pupuk Organik. Bahan Presentasi.

Hasibuan, M. 2005. Manajemen Sumber Daya Manusia. Edisi Revisi. Jakarta: Penerbit Bumi Aksara. 
Hidayati, M. R. Hidayat, dan Asmawit. 2015. Pemanfaatan Serat Tandan Kosong Kelapa Sawit Sebagai Media Pertumbuhan Jamur Tiram Putih. BIOPROPAL INDUSTRI 6(2): 73-80. http://ejournal.kemenperin.go.id/biopropal/article/view/837

Nasrul dan T. Maimun. 2009. Pengaruh Penambahan Jamur Pelapuk Putih (White Rot Fungi) pada Proses Pengomposan Tandan Kosong Kelapa Sawit. Jurnal Rekayasa Kimia dan Lingkungan 7(2): 194-199. http://www.jurnal.unsyiah.ac.id/RKL/article/view/226

Ndungi, F.N., P. Tuitoek, dan A.A. Aboud. 2017. Socio-Economic Status, Knowledge, Awareness and Attitudes of the Swahili Community in Relation to Dietary Habits, Obesity and Lifestyle Diseases. African Journal of Food, Agriculture, Nutrition and Development, 17(1), pp.11709-11725. https://doi.org/10.18697/ajfand.77.16335

Siregar, M., dan E. S. Ritonga. 2014. Tanggap Pertumbuhan Jamur Merang Terhadap Formulasi dan Ketebalan Media. Jurnal Dinamika Pertanian 29(3): 225-230. http://journal.uir.ac.id/index.php/dinamikapertanian/article/view/830

Syahza, A., D. Bakce, and B. Asmit. 2018. Increasing the awareness of palm oil plantation replanting through farmers training. Riau Journal of Empowerment 1(1): 1-9 https://doi.org/10.31258/raje.1.1.1

Wirasaputra, H. 2018. Pengaruh Ukuran Cacahan Dan Lama Pengomposan Terhadap Karakteristik Media Tanam Jamur Merang (Volvariella Volvaceae) Dari Tandan Kosong Kelapa Sawit. Bandar Lampung: Jurusan Teknik Pertanian Fakultas Pertanian Universitas Lampung. 